\title{
The genetics of brown adipocyte induction in white fat depots
}

\section{Leslie P. Kozak*}

Institute of Animal Reproduction and Food Research of Polish Academy of Sciences, Olsztyn, Poland

\section{Edited by:}

Patrick Seale, University of

Pennsy/vania, USA

\section{Reviewed by:}

Oh Yoen Kim, Yonsei University, South Korea

Martin Jastroch, Buck Institute for

Research on Aging, USA

\section{*Correspondence:}

Leslie P. Kozak, Institute of Animal Reproduction and Food Research Polish Academy of Sciences, ul. Tuwima 10, 10-747 Olsztyn, Poland. e-mail: I.kozak@pan.olsztyn.pl
Evidence that adult humans have functional brown adipose tissue has stirred interest in the possibility that the impressive effectiveness of induction of brown adipocytes to reduce obesity in mice may be translated to the human condition. A major focus recently on the identification of signaling and transcription factor that stimulate the induction of brown adipocytes has come from transgenic and gene KO models. However, these models have created a very complex picture of the regulatory mechanisms for brown fat induction. In this review insights into the critical regulatory pathways involved in brown adipocyte induction in the retroperitoneal fat depot of mice are described from quantitative trait locus (QTL) analysis of allelic variability determining Ucp1 levels and brown adipocyte induction in A/J vs. B6 mice. The key observation is that recombinant genotypes, found in recombinant inbred stains and backcross and intercross progeny, show transgressive variation for Ucp1 mRNA levels. These genetic crosses also show that the levels of Ucp1 mRNA are determined by interactions that control the levels of PPAR $\alpha, P G C-1 \alpha$, and type 2 deiodinase (DIO2) and that each factor is controlled by a subset of QTLs that also control Ucp1 expression. These results indicate that induction of $U_{c p} 1$ in the retroperitoneal fat depot involves synergy between signaling and transcription factors that vary depending upon the environmental conditions. Inherent in this model is the idea that there is a high level of redundancy that can involve any factor with the potential to influence expression of the core factors, PPAR $\alpha$, PGC-1a, and DIO2.

Keywords: Ucp1 mRNA, retroperitoneal fat depot, quantitative trait loci, transgressive variation, recombinant inbred strains of mice, backcross analysis, synergistic interaction of regulatory genes

\section{INTRODUCTION}

Approximately 20 transgenic/gene $\mathrm{KO}$ models have been described in the literature that increase the number of brown adipocytes in white fat depots and cause the transgenic mice to have increased resistance to diet-induced obesity (DIO;Kozak and Koza, 2010). Although the physiological basis for the resistance to obesity in many of these models is poorly described, the sheer numbers of transgenic models involved provide a compelling case for seriously considering a strategy to combat obesity in humans based upon an increase in brown adipocyte numbers. With the mouse genetic data and the rat pharmaceutical data as backdrops, new evidence that adult humans indeed have brown fat as discrete depots, detectable with PET imaging, has led to renewed efforts to identify mechanisms by which brown adipose tissue (BAT) can be induced in human tissues (Cypess et al., 2009; Van Marken Lichtenbelt et al., 2009; Virtanen et al., 2009). For this purpose it behooves us to review the information on BAT induction in the mouse to identify strategies that may be important for its induction in humans. This review will focus on insights that have come from the analysis of quantitative trait loci (QTL) that control variation in $U c p 1$ expression in the retroperitoneal white fat depot of $\mathrm{A} / \mathrm{J}$ and $\mathrm{C} 57 \mathrm{BL} / 6 \mathrm{~J}$ mice, in particular on the interaction of natural genetic variation with the environment in the control of $U c p 1$ and its utilization in reducing obesity. These genetic studies, together with what we know about the UCP1 function in the $U_{c p} 1^{-/-}$mice, indicate that simply reducing ambient temperature can significantly reduce adiposity in obese individuals.

\section{GENETIC VARIATION IN BROWN ADIPOSE TISSUE INDUCTION: AN AVENUE TO REDUCED OBESITY}

It has long been known that the expression of BAT was highly variable among different species, reflecting their particular environmental, developmental, and physiological traits and requirements (Smith and Horwitz, 1969). What was not realized, until the past $10-15$ years, was the rich genetic variation in BAT expression found within a species (Guerra et al., 1998), a variation that we have only begun to describe in mice and which will certainly be present in other species, including the human. Having described variation in BAT a longterm goal will be to determine the mechanism leading some animals to maximize this genetic trait of increased BAT that can be used to reduce fat stores. Current data indicate that some genetic constitutions make brown adipocyte induction in some individuals more responsive to the environment. Therefore, we need to determine when during development the capacity for modulation of BAT induction is maximal.

\section{INTERSCAPULAR BROWN ADIPOSE TISSUE}

In the mouse BAT first appears as a discrete tissue in the interscapular brown adipose tissue (iBAT) region at about 17 days of 
gestation (Houstek et al., 1988; Hirning et al., 1989; Giralt et al., 1990). Other discrete BAT depots are found on the top of the kidney in the axial region and in the thoracic cavity; however, when these discrete depots emerge developmentally in the mouse have not been reported to our knowledge (Cannon and Nedergaard, 2004). Following birth, iBAT continues to grow in size until about weaning by a mechanism that involves continued cell proliferation (Staszkiewicz et al., 2009). It has been reported that $65 \%$ of the nuclei of BBAT are labeled with BrdU in 10-day-old mice after injection with BrdU on days 3, 4, and 5. The size of iBAT at birth, its rate of growth postnatally and eventual size are identical between C57BL/6J and A/J mice (Xue et al., 2007), two strains which, as we will discuss below, show huge differences in brown adipocyte numbers in selective white fat depots and in their sensitivity to DIO.

\section{BROWN ADIPOCYTES IN WHITE FAT DEPOTS (WBAT)}

The induction of brown adipocytes in white fat depots by exposing rats to the cold or treating them with the $\beta 3$-adrenergic receptor agonist CL 316,243 has been described by several groups (Champigny et al., 1991; Himms-Hagen et al., 1994; Collins et al., 1997). However, the idea that inbred strains of mice vary in their induction of $U c p 1$ in the retroperitoneal fat depot and that this variable inductive response may account for the difference in DIO between A/J and C57BL/6J mice was first advanced by Surwit and coworkers (Collins et al., 1997). This idea suggested the exciting possibility that variant alleles for genes associated with $U c p 1$ expression and the brown adipocyte differentiation program are extant within the common inbred strains, thereby providing a genetic system to identify genes critical for the induction of brown adipocytes in white fat depots (Guerra et al., 1998). As we shall point out below, the genetic variation is restricted to the white fat depots and not observed in iBAT, a phenomenon that is largely recapitulated in the transgenic and gene $\mathrm{KO}$ models, that is, induction of brown adipocytes occurs in white fat depots of these transgenic models, but seldom in iBAT.

In the design of a QTL study to identify genes controlling brown fat induction, the selection of the fat depot becomes critical, because each fat depot has its own unique phenotype (Guerra et al., 1998). One is faced with the decision to select the white fat depot that one ascertains, with incomplete data, will be most amenable to analysis and most informative. First of all the iBAT in adult mice is not variable between A/J, B6, and 129/SvJ strains (Almind et al., 2007; Xue et al., 2007). However, large variations in levels of expression are found among tissues and each tissue varies independently among strains (Figure 1A). Among the visceral depots, gonadal fat shows large variation between strains, but the expression is low compared to that detected in the inguinal fat depot (Guerra et al., 1998). Mesenteric fat and retroperitoneal fat both have relatively high levels of expression and big differences between strains and they are therefore suitable for a QTL analysis. We selected the retroperitoneal fat for the QTL analysis because it is a fat depot also found in humans (the epididymal fat is not) and it is a well-defined tissue that can be more easily and rapidly excised from the mouse than mesenteric fat. Given these features of $U c p 1$ expression in different white fat depots, we cannot assume that the QTLs found associated with the control of $U c p 1$ mRNA levels
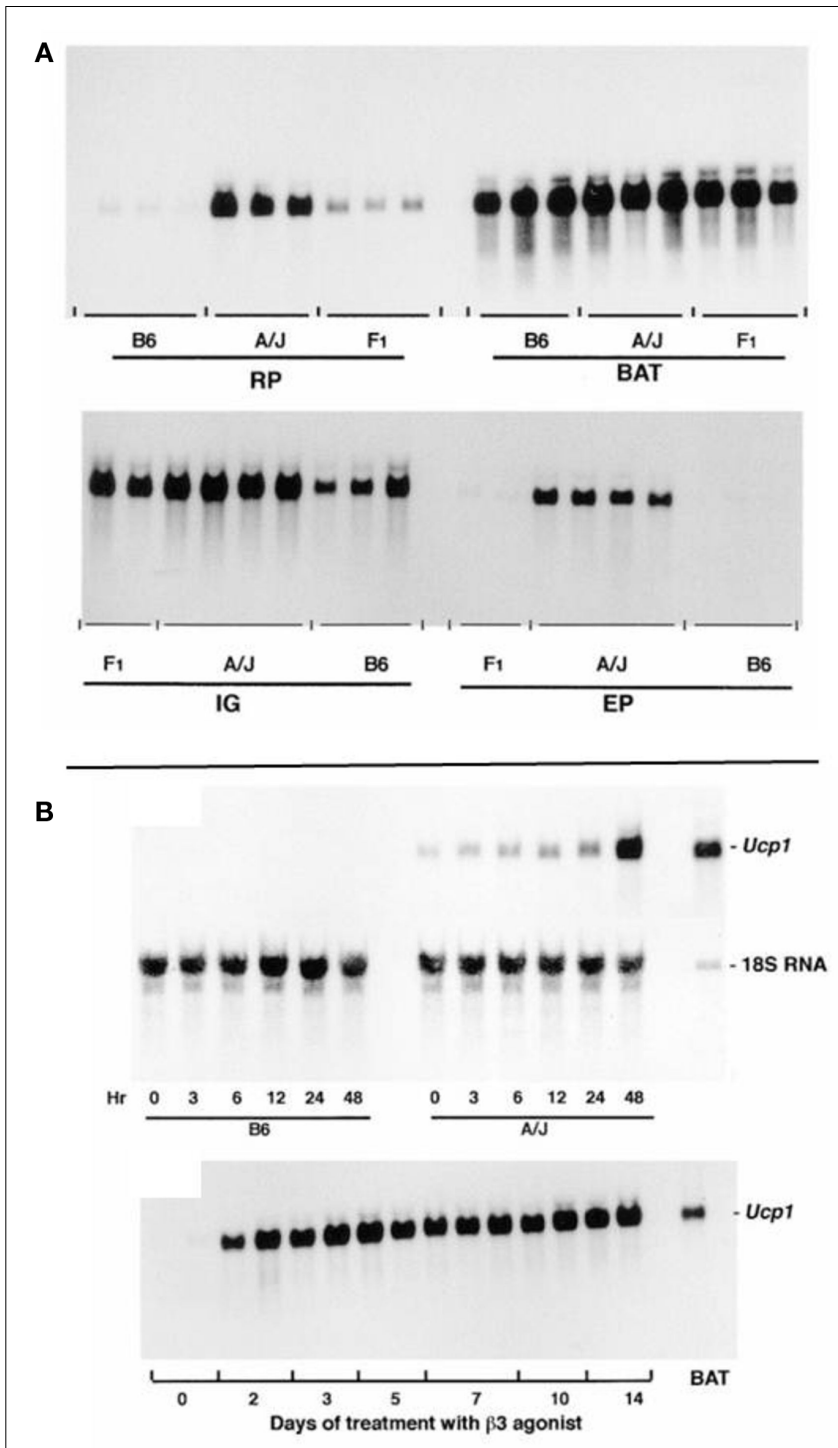

FIGURE 1 | (A) The levels of Ucp1 mRNA in the retroperitoneal fat $(R P)$, interscapular brown fat $(B A T)$, inguinal fat $(/ G)$, and epididymal fat $(E P)$ in total RNA isolated from $A / J, B 6$, and $(B 6 \times A / J) F 1$ mice are shown. Mice were treated with the $\beta 3$-adrenergic agonist $C L$ 316,243 for 7 days before isolation of RNA, at a time when induction of $U_{c p} 1$ mRNA had reached a plateau. Ten microgram of RNA from BAT was analyzed and $15 \mu \mathrm{g}$ from the other fat depots. (B) Northern blot analysis of total RNA. (Upper panel) The induction of $U_{c p} 1$ mRNA in the retroperitoneal fat pad of $B 6$ and $A / J$ mice when placed in the cold at $5^{\circ} \mathrm{C}$ as indicated between 0 and $48 \mathrm{~h}$. Total RNA was isolated from tissues pooled from three mice. Fifteen microgram of RNA was analyzed. (Lower panel) The induction of Ucp1 mRNA in the retroperitoneal fat pad after injection of the $\beta 3$-adrenergic agonist, $C L$ 316,243 , once a day in the late afternoon at a dose of $1 \mathrm{mg} / \mathrm{kg}$ body wt. RNA $(15 \mu \mathrm{g})$ from two mice was analyzed individually. A standard of $2.7 \mu \mathrm{g}$ of interscapular brown fat RNA was included on the gel.

in retroperitoneal fat are also controlling $U c p 1$ in other depots, especially the subcutaneous fat.

The time course for induction is similar for cold exposure and $\beta 3$-adrenergic agonist treatment in RP fat with increases in $U_{c p} 1$ mRNA evident by $3 \mathrm{~h}$ and stable maximal levels occurring in $48 \mathrm{~h}$ 
(Figure 1B). It is noteworthy that in $\mathrm{A} / \mathrm{J}$ mice some Ucp $1 \mathrm{mRNA}$ can be detected at room temperature and induction following exposure to the cold occurs within $3 \mathrm{~h}$.

\section{ALLELIC VARIATION AND RECOMBINANT INBRED STRAINS OF MICE}

The phenotypes of obesity and thermogenesis affected by $\beta$-AR agonists and ambient temperature in $\mathrm{A} / \mathrm{J}$ and $\mathrm{B} 6$ mice are complex. They involve up-regulation of $U c p 1$ and other molecular components of thermogenesis in existing brown adipocytes in the iBAT depot and de novo induction of new differentiated brown adipocyte populations in white adipose tissue; both of which are controlled in part by the sympathetic nervous system (Bartness and Bamshad, 1998). In addition, the phenotypes depend on variation in susceptibility to obesity at $23^{\circ} \mathrm{C}$ that exist between $\mathrm{A} / \mathrm{J}$ and B6 mice and are likely to be independent of BAT thermogenesis (Seldin et al., 1994; Guerra et al., 1998). To unravel the genetic and molecular complexity of brown adipocyte induction in white fat depots and determine its role in energy balance and obesity we utilized two genetic tools; the $\mathrm{A} \times \mathrm{B}$ recombinant inbred (RI) strains and progeny from backcross and intercross matings between $\mathrm{A} / \mathrm{J}$ and B6 mice and the RI strains (Koza et al., 2000). The A $\times$ B RI lines were formed by crossing $\mathrm{A} / \mathrm{J}$ and $\mathrm{B} 6$ mice and intercrossing the resulting $\mathrm{F} 1$ progeny to establish an $\mathrm{F} 2$ population that were then brother-sister mated for a minimum of 20 generations to establish inbred lines (Bailey, 1971; Taylor, 1981). If a genetic trait is complex, that is, it is controlled by allelic variation at more than one gene, then alleles from each gene associated with the trait in the $\mathrm{A} / \mathrm{J}$ and $\mathrm{B} 6$ parental strain will be fixed in new combinations in the different RI lines. Thus, each RI line with these novel recombinant chromosome patterns will provide potentially unlimited numbers of mice to establish the phenotypes determined by each gene or combinations of genes not present in the original parental lines. As shown in Figure 2, the levels of $U c p 1$ mRNA in the retroperitoneal fat depot of the parent $\mathrm{A} / \mathrm{J}$ mice exposed to a $4^{\circ} \mathrm{C}$ ambient temperature for 1 week were 40 times higher than that found in $\mathrm{B} 6$ mice (Guerra et al., 1998); however, the novel recombination of alleles in the RI lines generated a continuum of lines of mice with levels of $U c p 1$ that at the lower extreme in $\mathrm{A} \times \mathrm{B} 10$ mice were slightly less than those observed in $\mathrm{B} 6$ mice and at the other extreme in $\mathrm{A} \times \mathrm{B} 8$ mice they were 2.5 times higher than that occurring in $\mathrm{A} / \mathrm{J}$ mice (Figure 2A). The number of brown adipocytes in retroperitoneal fat of $\mathrm{A} \times \mathrm{B} 8$ mice approaches that detected in BBAT of $\mathrm{B} 6$ mice; however, despite having levels of Ucp1 mRNA similar to $\mathrm{A} \times \mathrm{B}$, $\mathrm{A} \times \mathrm{B} 15$ retroperitoneal fat has fewer brown adipocytes that can be detected with UCP1 immunohistology (Figure 2B). In addition to providing large numbers of mice with recombinant genotypes to establish phenotypes, comparisons of the strain distribution patterns of the levels of mRNA to the distribution of variant alleles of structural genes with allelic variation provided the first clues that several genes were involved in controlling induction of $U c p 1$ in white fat depots and preliminary assignment of the genes to specific chromosomes (Koza et al., 2000). The chromosomal linkage analysis of genes controlling $U c p 1$ induction will be discussed later with the QTL analysis of brown fat induction in intercross and backcross progeny.

\section{GENETIC VARIABILITY IN THE INDUCTION OF BROWN FAT AND THE OBESE PHENOTYPE}

Two questions essential to the relationships between constitutive expression of iBAT and inducible levels of wBAT and susceptibility to DIO can be addressed with the RI lines. The first question is whether the potential for induction of brown adipocytes in white fat determines the development of obesity in the absence of adrenergic stimulation by cold exposure or $\beta 3$-AR agonist treatment. In other words, does the constitutive level of Ucp 1 mRNA, which in mice comes from the Ucp 1 expressed in the discrete iBAT depots and does not show strain variation (Coulter et al., 2003; Almind et al., 2007; Xue et al., 2007), affect the development of obesity. Conceivably this might occur if a cafeteria-like diet directly induced thermogenesis through activation of iBAT Ucp1 as proposed by Rothwell and Stock (1979). Accordingly, parental A/J, B6, and six RI lines with variable levels of $U c p 1$ mRNA inducible in white fat were fed a high fat/high sucrose obesogenic diet for 18 weeks at an ambient temperature of $23^{\circ} \mathrm{C}$ to establish an obese state for each line (Figure 3A). Weight gain averaged from $11 \mathrm{~g}$ in $\mathrm{A} / \mathrm{J}$ mice to $26 \mathrm{~g}$ in $\mathrm{B} 6$ mice as previously observed (Collins et al., 1997); however, A $\times$ B8 mice, which had the highest capacity to induce Ucp1 mRNA in white fat depots upon adrenergic stimulation, gained $24 \mathrm{~g}$ of fat, which was not significantly different than that observed for B6 mice, which had the lowest level of $U c p 1$ expression (Figure 3A; Guerra et al., 1998). This result indicates that in mice fed a high fat diet at $23^{\circ} \mathrm{C}$, the capacity for induction of $U c p 1 / \mathrm{BAT}$ by cold exposure in white fat had no impact on the development of DIO at normal ambient temperatures $\left(23^{\circ} \mathrm{C}\right)$. One could argue that despite similarities in the levels of Ucp 1 mRNA or protein in the iBAT of A/J and B6 mice, some unknown form of sympathetically mediated activation of iBAT-dependent diet-induced thermogenesis exists among $\mathrm{A} / \mathrm{J}$ mice at $23^{\circ} \mathrm{C}$ to reduce DIO. However, the suppression of increased DIO in B6 Ucp1 KO mice, with no capacity for UCP1-dependent thermogenesis by a brown adipocyte, indicates that diet-induced thermogenesis by brown fat is not a factor that increases susceptibility to DIO at $23^{\circ} \mathrm{C}$ (Kozak, 2010).

The second question, whether variation in the induction of Ucp 1 by adrenergic signaling has an impact on the obese state, was addressed in the second part of the experiment. Using the same eight lines of mice with variable levels of obesity, described in Figure 3A, were treated with the $\beta 3$-AR agonist, CL 316,243, for 24 days while continuing to be fed the high fat diet (Figure 3B). All mice lost body weight, however, the amount of body weight lost depended upon the levels of $U c p 1$ mRNA that were induced in the white fat depots (Figures 3B,C; Guerra et al., 1998), that is, mice with higher levels of adrenergically induced $U c p 1$ mRNA in retroperitoneal fat lost more body weight. Thus, genetically determined variability in the induction of brown adipocytes in white fat depots by adrenergic stimulation is a significant factor in reducing obesity in response to adrenergic stimulation by exposure to cold or drugs. Accordingly, pharmaceuticals that are able to induce the number of brown adipocytes in discrete BAT depots or white fat depots could be an effective anti-obesity strategy. 
A

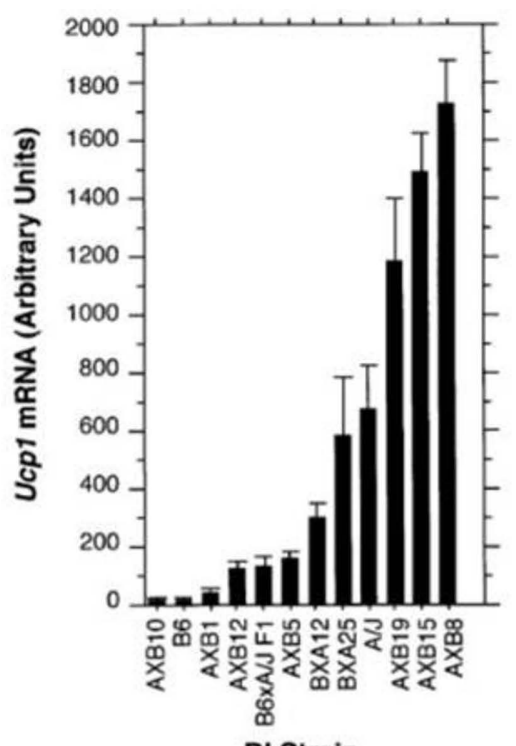

RI Strain

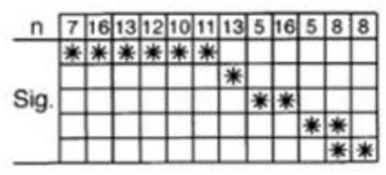

B

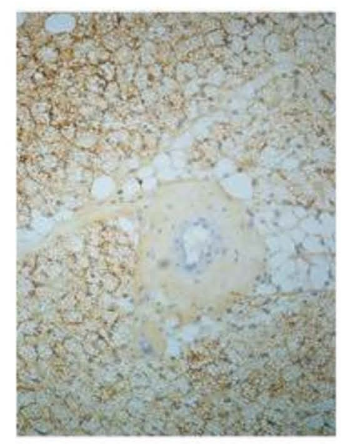

wBAT AXB15

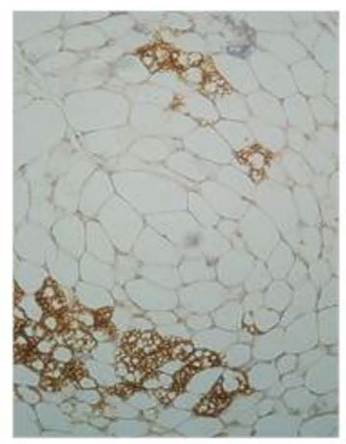

WBAT AXB8

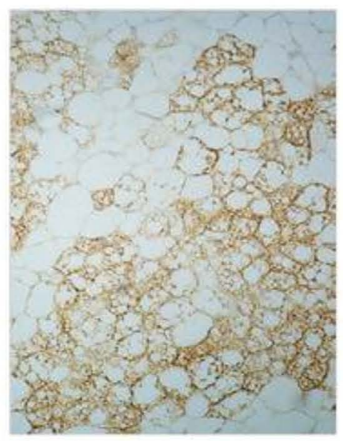

FIGURE 2 | (A) Bar graph shows Ucp1 mRNA levels in the retroperitoneal fat pad from parental $A / J, B 6, F 1$ hybrid, and RI strains of mice derived from the parental mice. Mice were housed at $5^{\circ} \mathrm{C}$ in groups of two to three mice per pen for 7 days before the isolation of RNA. Induction in the cold is similar to that caused by a $\beta 3$-adrenergic agonist. Data are presented as the mean $\pm \mathrm{SE}$. The number of animals $(n)$ of each strain and the results of statistical analyses by ANOVA (Fisher's PLSD test in Statview 4.1) are given in the lower chart.
Strains sharing asterisks in a row are not significantly different from each other at $P=0.05$. (B) UCP1 immunohistology of paraffin-embedded sections from interscapular brown fat (iBAT) and retroperitoneal fat (WBAT) from $\mathrm{A} \times \mathrm{B} 8$ and $\mathrm{A} \times \mathrm{B} 15$ mice demonstrates the organization of brown adipocytes into clusters that resemble fields of densely packed brown adipocytes characteristic of iBAT. The size of these regions in wBAT may be quite variable, depending upon the strength of the induction.

\section{CHROMOSOMAL MAPPING OF GENES CONTROLLING BAT INDUCTION BY OTL ANALYSIS}

Given that there is probably no anti-obesity strategy in mice and rats that is as effective as the induction of brown adipocytes in white fat depots, identifying genes that could enhance the induction of brown adipocytes is an important goal. The analysis of the RI strains provided evidence that the induction of brown adipocytes in white fat upon adrenergic stimulation involved multiple genes; however, neither the number of genes nor their chromosomal location were able to be determined from analysis of strain distribution patterns alone (Koza et al., 2000). To identify the genes controlling brown adipocyte induction, we pursued a QTL analysis in which the primary phenotype was Ucp 1 mRNA levels in retroperitoneal fat depots after 7 days at $5^{\circ} \mathrm{C}$, initially measured 


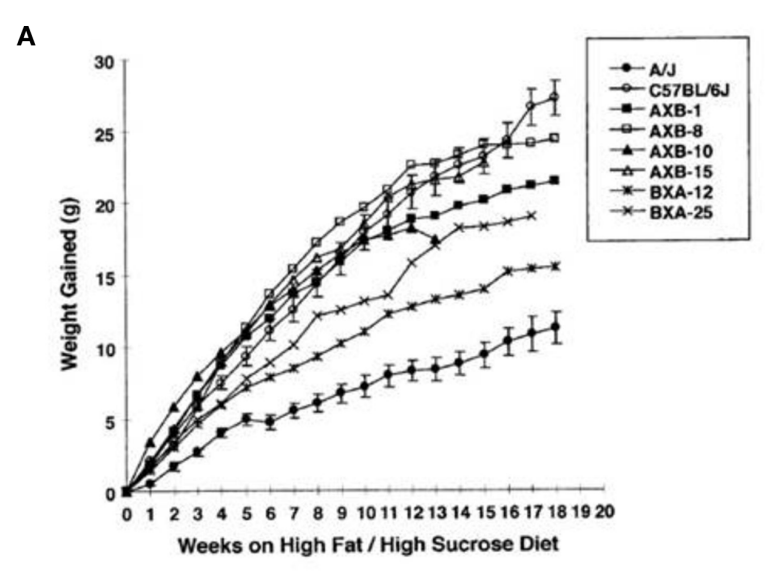

B

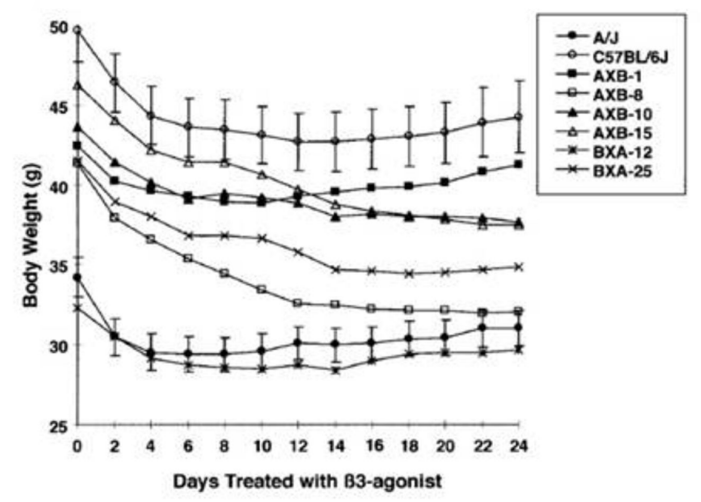

C

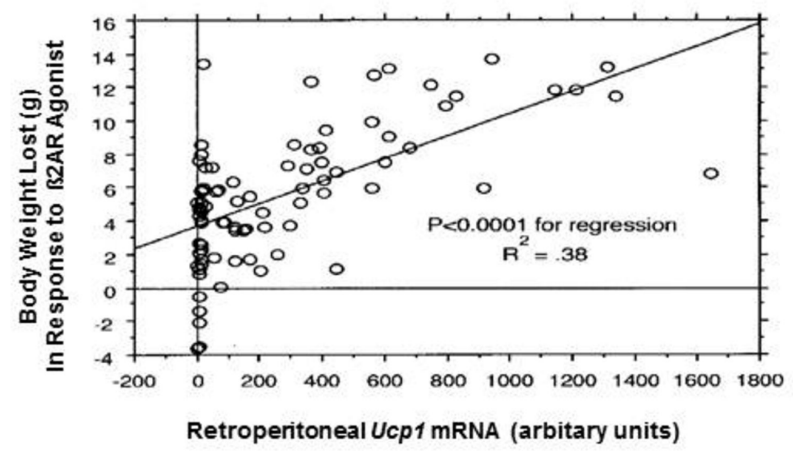

FIGURE 3 | (A) Body weight gained by parental and RI strains fed a high fat/high sucrose diet (Research Diets 12331) starting at 7 week of age and continuing for 18 week. (B) After 18 week, mice continued to be fed the high fat/high sucrose diet and were also treated with the $\beta 3$-adrenergic agonist, CL 316,243, as described (Guerra et al., 1998). Changes in body weight are shown. The mean $\pm \mathrm{SE}$ for the $\mathrm{B} 6$ and $\mathrm{A} / \mathrm{J}$ parental strains are shown, whereas only the means have been plotted for the RI stains. The number of mice in each group ranges from 9 to 12. (C) Regression analysis to evaluate the effects of Ucp1 mRNA in the retroperitoneal fat on body weight loss. $P$ is an estimator of the significance of the regression. $R^{2}$ is the coefficient of determination; it is the proportion of the dependent variable that is explained by the independent variable. $N$ was 86 .

by semi-quantitative Northern blots (Guerra et al., 1998) and later by quantitative RT-PCR with TaqMan probes using the ABI sequence detection system (Koza et al., 2000). Since there was a strong correlation between inducible Ucp 1 mRNA and the content of brown adipocytes determined by immunostaining for UCP1 in the tissues of mice exposed to the cold (Guerra et al., 1998), the Ucp 1 mRNA sub-phenotype is a reliable surrogate for brown adipocyte induction. The conversion of a white fat depot devoid of brown adipocytes to one rich in brown adipocytes requires the activation of brown fat specific adipogenesis, mitochondrial biogenesis, and increased innervation and vascularization (Cannon and Nedergaard, 2004). However, the most specific molecular marker change is the activation of $U c p 1$. Mice with an inactivated $U c p 1$ gene cannot tolerate an acute exposure to the cold because they have lost an important mechanism for thermogenesis (Enerback et al., 1997). Since the Ucp 1 expression phenotype is near the end of a complex pathway from cold receptors on the surface of the skin to the processing of signals in the central nervous system that activate signaling and transcription factors in the adipocyte capable of being converted to a brown adipocyte, variable activity of any gene involved at any step of this complex process can be revealed by QTL analysis, if its effects on the levels of $U c p 1$ mRNA are sufficiently robust and precise. Indeed the expression for several genes [PPAR $\alpha$, type 2 deiodinase (DIO2), and PGC- $1 \alpha$ ] implicated in $U c p 1$ expression are highly variable in white fat of cold exposed mice and show highly significant correlations with Ucp1 expression (Coulter et al., 2003; Xue et al., 2005).

Based upon evidence that multilocular brown adipocytes in white fat depots were not labeled with BrdU in rats treated with the $\beta 3$-AR agonist CL 316,243 (Himms-Hagen et al., 2000), we assumed that cell proliferation of a progenitor brown adipocyte does not occur in white fat depots of adult mice, unlike the cell proliferation that occurs in interscapular BAT during chronic cold exposure (Bukowiecki et al., 1982). Therefore, genes controlling the proliferation of adipocyte progenitors in white fat are assumed not to be involved in the induction of brown adipocytes in white fat during the first 7 days of adrenergic stimulation. Whether cell proliferation occurs following long term cold exposure is another question. This assumption is supported by the evidence on gene expression which showed that maximal levels of $P g c-1 \alpha$ mRNA are reached within 1 day of adrenergic stimulation and significant levels of $U c p 1$ mRNA can be detected in $\mathrm{A} / \mathrm{J}$ mice within $3 \mathrm{~h}$ of being exposed to the cold (Coulter et al., 2003). Furthermore, changes in adipocyte morphology showing the emergence of a multilocular adipocyte from a unilocular adipocyte are consistent with the hypothesis that mature unilocular white adipocytes are directly converted to multilocular brown adipocytes (Cinti, 2002). If in fact brown adipocytes arise from mature white adipocytes, then it suggests that the brown adipocyte differentiation program is established during a window of postnatal adipose tissue development between 10 and 21 days of age when brown adipocytes transiently appear and then disappear (Xue et al., 2007). We postulate that since not all adipocytes look like brown adipocytes, this differentiation process has been implemented in selected adipocytes, which resemble mature white adipocytes under certain conditions, at weaning and in adults following adrenergic stimulation by a mechanism that rapidly initiates mitochondrial biogenesis and Ucp 1 expression. Such a mechanism may not even involve further epigenetic modification of chromatin structure, but merely involve activation of PKA signaling and other mechanisms controlling 
cAMP levels. Viewed from this perspective the search for candidate genes controlling the induction of brown adipocytes becomes focused on genetic mechanisms determining the sub-population of white adipocytes in a white fat depot with a chromatin structure unique for brown adipocytes. The brown adipocytes in traditional white fat depots may be masquerading as white adipocytes until they are adrenergically stimulated. A research goal will be to identify the molecular basis of their chromatin structure that enables a rapid transcription of brown adipocyte specific genes. A component of such a mechanism could be RIP140 (Leonardsson et al., 2004; Christian et al., 2005).

\section{THE BACKCROSS MODEL}

The molecular analysis of $U c p 1$ regulation has not revealed any brown fat specific signaling or transcription molecules; however, a regulatory model in which brown fat specific expression is determined by a modular molecular mechanism is consistent with existing data (Hansen and Kristiansen, 2006; Kajimura et al., 2008). If an interactive molecular mechanism controls brown adipocyte induction in white fat, perhaps the interactive transgressive mechanism revealed by the analysis of RI lines and backcross and intercross progeny may be the manifestation of such a mechanism at the gene level.

Two cohorts of approximately $400(\mathrm{~A} / \mathrm{J} \times \mathrm{B} 6) \mathrm{F} 1$ backcross mice were generated to test the idea that the known transcription factors of $U c p 1$ were associated with $U c p 1$ induction phenotypes following 7 days in the cold. Mice in cohort 1 were fed a standard low fat chow ( $11.9 \mathrm{kcal} \%$ fat $)$ diet from weaning to 8 weeks of age when the mice were exposed to cold at $5^{\circ} \mathrm{C}$ for 7 days. Mice in cohort 2 were fed a high fat diet containing $58 \mathrm{kcal} \%$ fat (Research Diets 12331) from weaning until the end of the cold exposure (mice were subjected to cold exposure at $5^{\circ} \mathrm{C}$ for 7 days at 8 weeks of age). The rationale behind conducting a QTL analysis of mice fed a high fat diet was to assess whether the genes controlling induction of Ucp 1 were influenced by a cafeteria-like diet, thereby protecting the animal against DIO through increased thermogenesis (Rothwell and Stock, 1979; Cannon and Nedergaard, 2004).

Prior to analysis of gene expression in the backcross mice we assessed the variation in expression of genes implicated in Ucp 1 transcription between $\mathrm{A} / \mathrm{J}$ and $\mathrm{B} 6$ mice exposed to the cold for 7 days. Differences in expression between the mouse strains were too small for analysis in backcross mice (less than twofold) for the following genes: Pref1, Nfe2l2, SREBP-1c, PPAR $\gamma, \operatorname{PPAR} \gamma 2$, CEBP$\alpha$, CEBP- $\beta$, CEBP- $\delta$, FoxC2, and $\beta 3$-adrenergic receptor. Robust differences between B6 and A/J were found for PPAR $\alpha$, and Dio2 and modest variation for PGC-1 $\alpha$. In addition, the high fat diet showed variable increases in the expression of these latter genes (Table 1). The highly significant correlations were found between Ucp1 and Pgc-1 $\alpha$, Ppar $\alpha$ and Dio2 (Coulter et al., 2003; Xue et al., 2005). In mice fed a low fat chow diet approximately $55 \%$ of the variance in $U c p 1$ levels is associated with the variance in $P g c-1 \alpha$, but less $(16 \%)$ in mice fed the high fat diet (Figure 4). Similar relationships were found between Ucp1 and Ppara and Dio2 (Xue et al., 2005). In addition, similar to the transgressive variation found for $U c p 1$ in the RI strains, novel allelic recombinations in the backcross progeny generated transgressive phenotypes for
Table 1 | Effects of a high fat diet on Pgc-1 $\alpha$ and Ucp1 mRNA levels.

\begin{tabular}{lllll}
\hline Strain and mRNA & LFD mRNA & HFD mRNA & $P$-value & $\boldsymbol{n}$ \\
\hline AJ Ucp1 & $222 \pm 20$ & $186 \pm 42$ & 0.43 & 12 \\
B6 Ucp1 & $9.5 \pm 2$ & $33 \pm 10$ & 0.02 & 12 \\
B $\times$ AF1 Ucp1 & $38 \pm 7$ & $55 \pm 12$ & 0.22 & 12 \\
AJ Pgc-1 $\alpha$ & $13 \pm 1$ & $21 \pm 2$ & $3.3 \times 10^{-4}$ & 12 \\
B6 Pgc-1 $\alpha$ & $5.7 \pm 0.3$ & $9.7 \pm 0.9$ & $1.1 \times 10^{-4}$ & 12 \\
B $\times$ AF1 Pgc-1 $\alpha$ & $7.4 \pm 0.4$ & $9.3 \pm 0.6$ & 0.02 & 12 \\
BC Ucp1 & $67.4 \pm 2$ & $77.8 \pm 3$ & $7.3 \times 10^{-3}$ & 400 \\
BC Pgc-1 $\alpha$ & $8.2 \pm 0.2$ & $11.7 \pm 0.3$ & $1.6 \times 10^{-24}$ & 400 \\
\hline
\end{tabular}

$A / J, C 57 B L / 6 J(B 6),(B \times A) F 1$ and backcross mice were exposed to cold at $5^{\circ} \mathrm{C}$ for 7 days while on chow (4.5 wt \% fat, LFD) or high fat diets (36 wt \% fat, HFD) from weaning until the end of cold exposure. Pgc-1 a mRNA levels increased $43 \%$ and Ucp 1 levels $15 \%$ in backcross mice on a high fat diet.

each of these genes critical to wBAT induction. The significance of this transgressive variation is that perturbations in the expression levels of these transcription factors through allelic variation underlying the QTLs, together with environmental factors, like diet and ambient temperature, will affect the induction of $U c p 1$ and wBAT. That a large number of transgenes and gene KOs affect wBAT induction through effects on PPAR $\alpha, \mathrm{PGC}-1 \alpha$, and DIO2 becomes predictable.

Using MIT markers chromosomal regions associated with levels of Ucp 1, Ppara, $P g c-1 \alpha$, and Dio2 mRNA in backcross progeny were mapped. The chromosomal linkage studies showed that QTLs on Chromosomes 2, 3, 8, and 19, which are associated with induction of $U c p 1$, were also associated, in part, with induction of Ppar $\alpha, P g c-1 \alpha$, and Dio2. Furthermore, significant differences were observed for the core QTLs, defined as those controlling Ucpl expression (Figure 5). In mice fed a high fat diet, Chromosomes 2, 3, 8, and 19 were associated with levels of $U c p 1$ and Ppar $\alpha$ mRNA; however, unlike Ucp 1 expression, not all QTLs were involved with the Ppar $\alpha, P g c-1 \alpha$, and Dio2. These associations are shown in Figure 5, for backcross mice fed both the low and high fat diets. The complexity of QTLs is greater for mice fed the chow diet than the high fat diet. The identities of the genes in the QTLs which determine the expression phenotypes are not proven, though plausible candidates exist. The fact that the peak of the QTL on Chromosome 8 is very close to Ucp 1 provides a candidate to account for variation in Ucp 1 mRNA levels, but it would require a mechanism by which $U c p 1$ also regulates $P P A R \alpha$. Other genes under the peak of the Chromosome 8 QTL appear to be better candidates at this time. The QTL on Chromosome 15 lies close to the location of Ppara. Confirmation that Ppar $\alpha$ was a one of the variant alleles could not be confirmed with the Ppara KO mouse (Xue et al., 2005). These linkage associations of Ucp1 and these transcription factors are consistent with transgressive variation and the synergy associated with $U c p 1$ induction. A change in the fat and carbohydrate content can change the levels of the transcription factors to select an alternative signaling and transcription factor for wBAT induction. A practical outcome of such a mechanism is that it enhances the range of drug targets for induction of wBAT. 

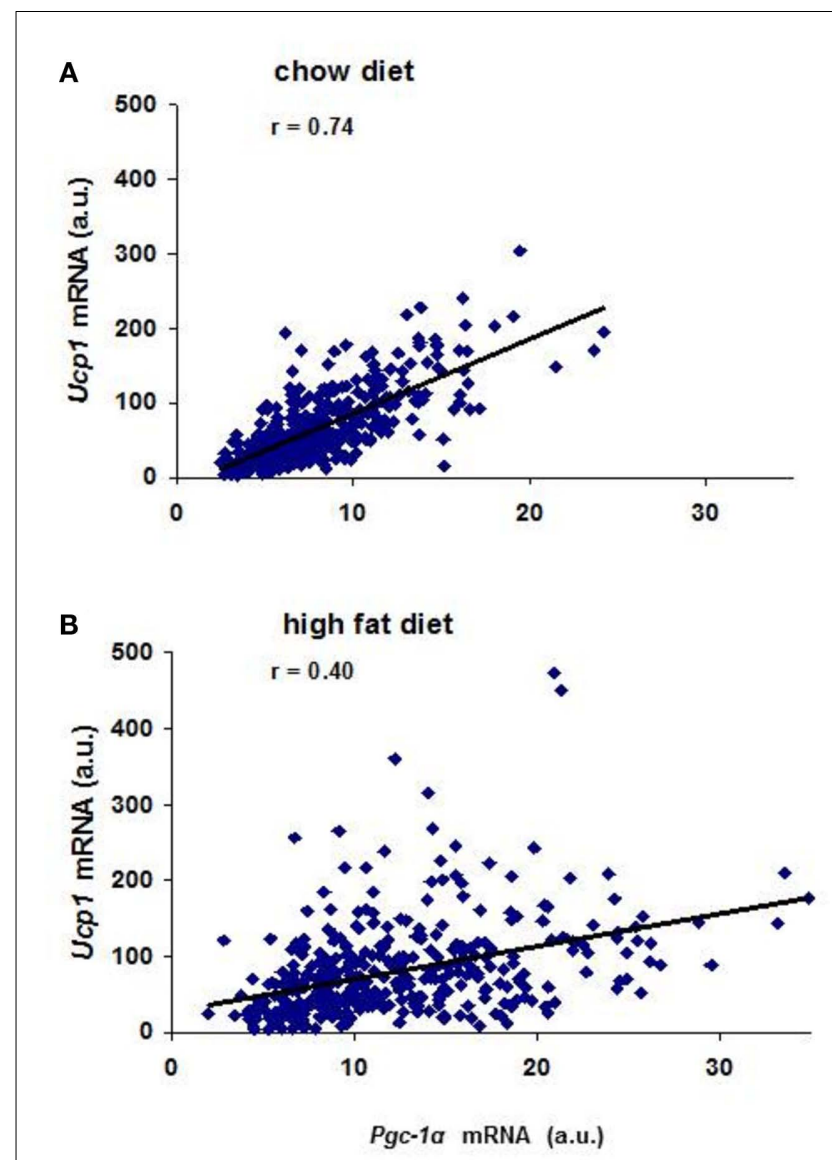

FIGURE 4 | (A) Correlation between Pgc-1 $\alpha$ and $U_{c p} 1$ mRNA levels in mice fed a 4.5 wt $\%$ fat diet. Approximately $400(B 6 \times A / J) F 1 \times A / J$ backcross males 8 weeks of age were exposed to $5^{\circ} \mathrm{C}$ for 7 days. (B) Correlation between Pgc-1 $\alpha$ and $U_{c p} 1$ mRNA levels in mice fed a $58-k c a l \%$ fat diet. $P g c-1 \alpha$ and $U_{c p} 1$ mRNA levels were determined in 400 backcross animals maintained on a high fat diet from weaning to 8 weeks of age and then exposed to the cold for 7 days.

\section{TRANSGRESSIVE VARIATION: A MANIFESTATION OF SYNERGISTIC INTERACTIONS BETWEEN OTLS AND TRANSCRIPTION FACTORS AND SIGNALING MOLECULES THAT CONTROL UCP1 EXPRESSION}

Synergy in the expression of Ucp 1 has been observed at two different levels, first at the level of interacting genes and second at the level of transcription and signaling factors implicated in $U c p 1$ expression. The strain distribution of Ucp 1 mRNA levels in RP fat of cold exposed $\mathrm{A} \times \mathrm{B}$ and $\mathrm{B} \times \mathrm{A}$ RI mice provided clear evidence for the existence of transgressive variation for Ucp 1 expression, that is, the production of offspring with phenotypes that exceed the parental extremes (Figure 2; Guerra et al., 1998; Koza et al., 2000). The novel combinations of alleles at several loci contributing to $U c p 1$ expression in RI strains result in higher levels than that which occurs in the $\mathrm{A} / \mathrm{J}$ strain. The gene interactions determining transgressive variation have been observed in global studies of gene expression in mice and yeast but rarely analyzed for specific genes (Brem and Kruglyak, 2005; Shockley and Churchill, 2006).The first QTL analysis of the $(\mathrm{B} 6 \times \mathrm{A} / \mathrm{J}) \mathrm{F} 1 \times \mathrm{A} / \mathrm{J}$ backcross mice identified

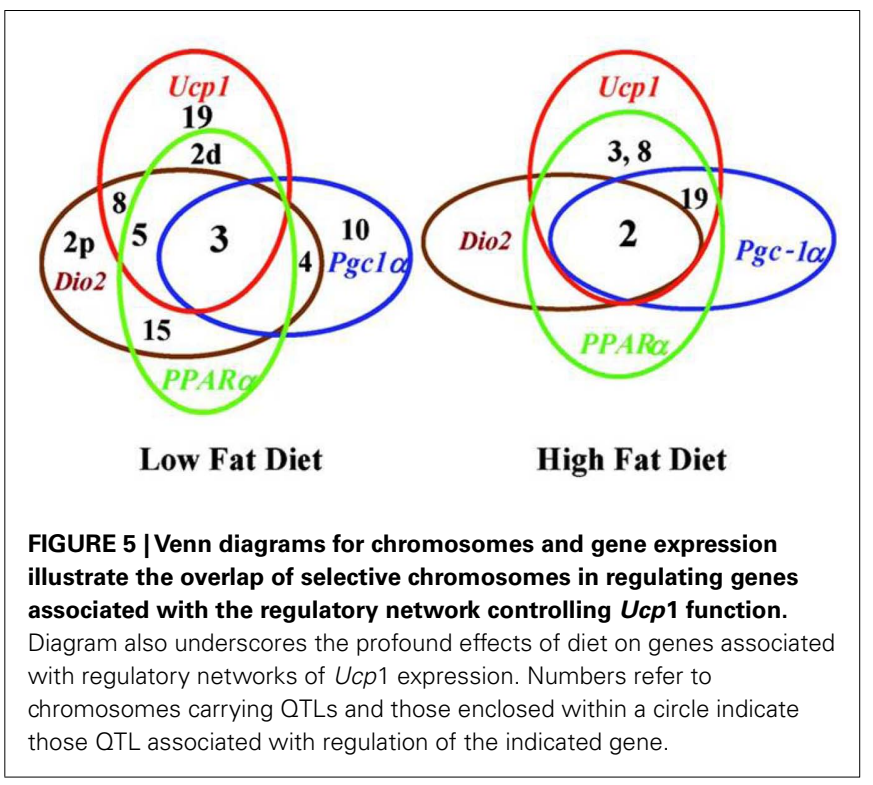

Chromosomes 2, 3, 8, and 19 to be associated with $U c p 1$ expression and similar to the RI line data, the levels of $U c p 1$ in the backcross progeny had a range of expression that also showed transgressive variation, that is, they exceeded the levels of $U c p 1$ expression found in the $\mathrm{A} / \mathrm{J}$ mice, approaching those found in $\mathrm{A} \times \mathrm{B} 8$ mice (Koza et al., 2000; Coulter et al., 2003). Positive effects on Ucp 1 mRNA levels are associated with an A/J allele at the peak QTL on Chromosomes 2, 3, and 8, whereas the B6 allele on the QTL for Chromosome 19 was associated with elevated Ucpl. Accordingly, transgressive variation is based in part upon the interaction of a variant gene encoded by the B6 allele on Chromosome 19 with a variant gene on Chromosomes 2, 3, and/or 8 encoded by an $\mathrm{A} / \mathrm{J}$ allele. Sixteen sets of mice with allelic assignments possible at Chromosomes 2, 3, 8, and 19 are rank ordered with respect to Ucp 1 mRNA levels (Table 2). As predicted from the strain distribution pattern of the RI lines, $\mathrm{A} \times \mathrm{B} 8$, and seven other strains with levels that exceed A/J mice have A/J alleles at QTLs on Chromosomes 2, 3 , and 8, but a B6 allele on Chromosome 19. This interpretation was further tested with an intercross of two RI lines, $\mathrm{A} \times \mathrm{B} 8$ and $\mathrm{A} \times \mathrm{B} 10$ that would assess the association of $\mathrm{A} / \mathrm{J}$ and $\mathrm{B} 6$ alleles at the QTLs on Chromosomes 8 and 19. As shown in Figure 6A strong synergistic interactions elevate Ucp 1 expression in mice homozygous for the $\mathrm{A} / \mathrm{J}$ allele at D8Mit 45 and homozygous for the B6 allele on Chromosome 19 near D19Mit86 ( 20 cM). Thus, an $\mathrm{A} / \mathrm{J}$ allele at $D 19 \mathrm{Mit} 86$ shows dominance in suppressing the effects of an A/J allele near D8Mit 45 at $40.5 \mathrm{cM}$ (Figure 6B). The Chromosome 8 QTL affecting $U c p 1$ mRNA production is near the $U c p 1$ gene itself at $37.7 \mathrm{cM}$. It is possible that $U c p 1$ itself is structurally variable between $\mathrm{A} / \mathrm{J}$ and $\mathrm{B} 6$ mice and that it directly interacts by a trans-mechanism with a gene located near D19Mit86. In our efforts to identity the QTLs, congenic lines were generated for QTLs on Chromosomes 8 and 19; however, lines carrying a single QTL failed to show differences in Ucp1 expression (L. P. Kozak, unpublished results).

We have shown how trans-acting genes on known chromosomes in a very specific QTL system controlling $U c p 1$ expression 
Table 2 | Strain distribution pattern in RI lines in relationship to Ucp1 mRNA levels.

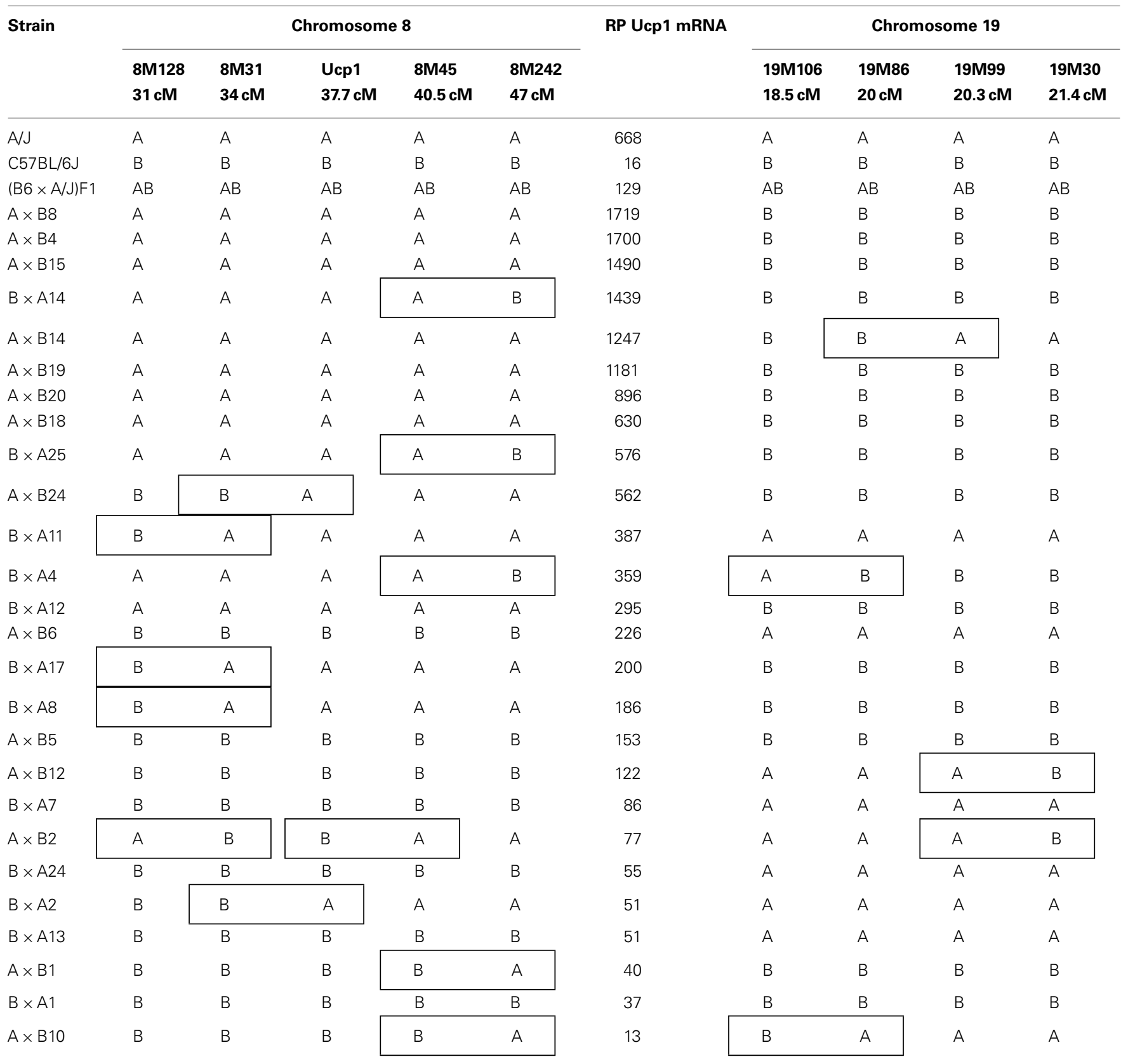

Genotyping data in this table was assembled from the RI strain SDP's in the Mouse Genome Database (The Jackson Laboratory, Bar Harbor, Maine, http://www.informatics.jax.org/riset_form.shtml) and by genotyping of the RI strain DNA's. Microsatellite markers and relative cM positions (MGD) for chromosomes 8 and 19 are noted on the top of the table. Boxed in genotypes indicate RI strains with a recombinations between the markers of each chromosome.

are giving rise to transgressive expression at the molecular level. Previously it was shown that the occurrence of spontaneous ovarian teratomas in RI strains was greater than that observed to occur between progenitor strains (Eppig et al., 1996). A genetic analysis of morphological traits of yeast has revealed a complex QTL system with transgressive variation which has been correlated with gene expression analysis to produced results similar to the regulation of Ucp 1 and brown fat induction (Nogami et al., 2007). Others have conducted a methodological global gene expression analysis of liver and kidney with chromosome substitution strains between $\mathrm{A} / \mathrm{J}$ and B6 mice to assess allelic effects on gene expression and found that allelic variation at several chromosomes affect expression of 4209 transcripts (Shockley and Churchill, 2006). Many of the transcripts had levels of expression that exceeded those found in the parental strains, suggestive of transgressive variation (Shockley and Churchill, 2006).

Evidence from backcross and intercross analyses indicated that interactions between a B6 allele on Chromosome 19 with an A/J 

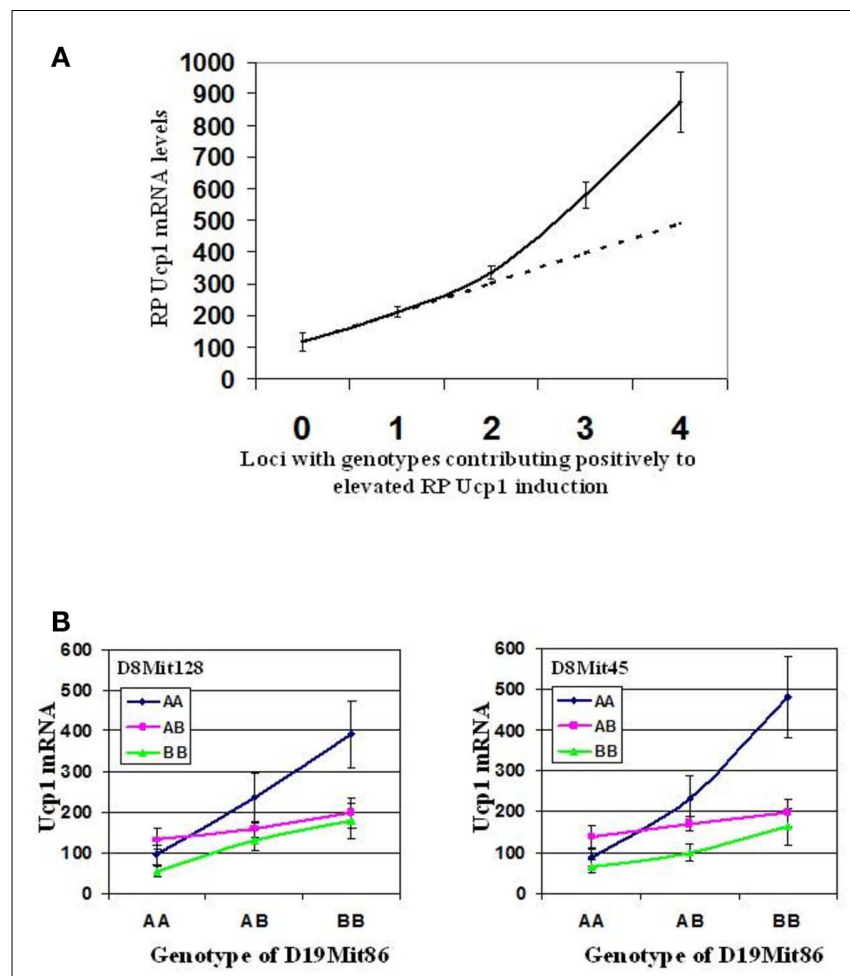

FIGURE 6 | (A) Synergistic effect of Iba QTLs on retroperitoneal Ucp1 mRNA induction. This is a graphic representation demonstrating the complex epistatic and additive interactions between the four Iba loci. The solid line represents the experimental retroperitoneal fat (RP) Ucp1 mRNA induction levels in relationship to the number of positive contributing loci. The dashed line indicates the theoretical value if interactions between Iba loci were only additive. (B) Effect of interactions between loci near Ucp1 (D8Mit45, 40.5 cM; D8Mit128, $31 \mathrm{cM})$, and D19Mit86 (20 cM) on retroperitoneal fat $U_{c p 1}$ mRNA induction in 286 intercross progeny from $\mathrm{A} \times \mathrm{B} 10$ and $\mathrm{A} \times \mathrm{B} 8$. Line interaction plots demonstrate a strong epistatic interaction between loci on chromosomes 8 and 19. This interaction appears to be stronger for D8Mit45, a locus nearer to Ucp1 than for D8Mit 128, the major QTL defined in the $(\mathrm{A} / \mathrm{J} \times \mathrm{B} 6) \mathrm{F} 1 \times \mathrm{A} / \mathrm{J}$ backcross. Interaction plot data was generated using Statview v.4.5.

allele on Chromosome 8 and possibly Chromosome 3 synergize to maximize expression of Ucp 1. Since we also showed that these QTLs also determined variation in the levels of PPAR $\alpha, \operatorname{PGC}-1 \alpha$, and Dio2 (Xue et al., 2005), we speculate that these transcription factors and signaling molecules, as well as others, interact synergistically to maximize the expression of $U c p 1$. An overview of the signaling and transcription pathways controlling Ucp 1 expression is presented in Figure 7. Below each of the factors is a number that indicates the ratio of expression for that factor between $\mathrm{A} / \mathrm{J}$ and B6 mice. It is apparent that all increases in expression are found for factors that lie downstream of PKA. There were no differences in expression for PKA or other factors that are upstream of PKA. Therefore, while retinoblastoma $(R b)$ and Foxc 2 have been implicated in the induction of brown adipocytes in transgenic mice and cell cultures (Cederberg et al., 2001; Hansen et al., 2004), variations in their expression are not associated in determining the differences in the induction of $U c p 1$ in $\mathrm{A} / \mathrm{J}$ and B6 mice. However, the key feature of this system for the control of $U c p 1$ is that

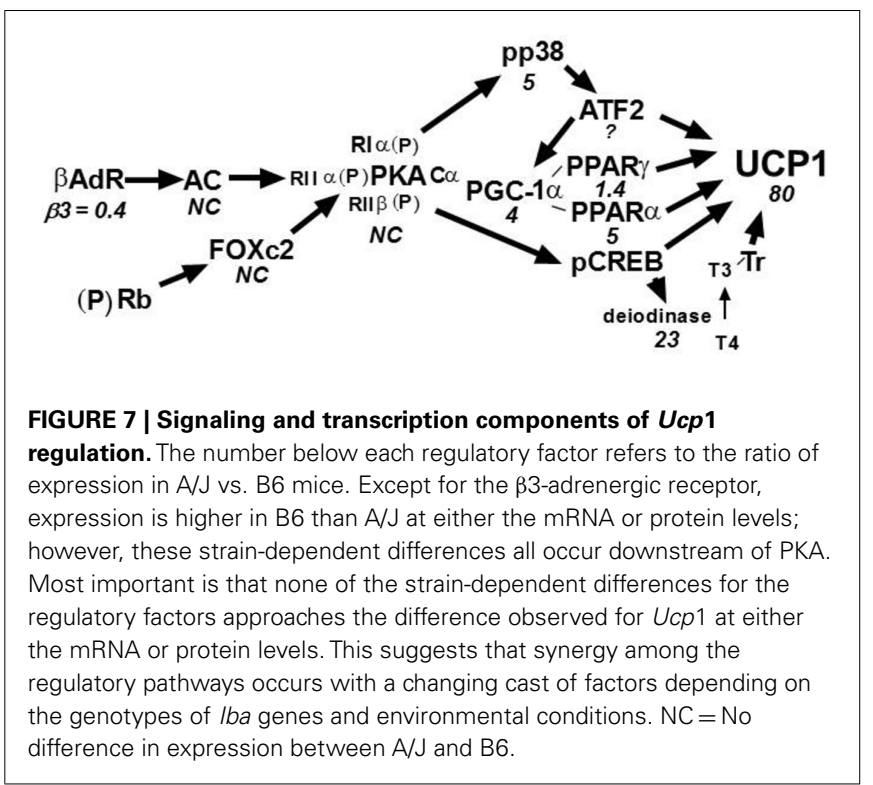

while many regulatory components, known to have essential roles in $U c p 1$ expression, have elevated expression in $\mathrm{A} / \mathrm{J}$ mice, relative to $U c p 1$ the differences in expression are very modest. For example, there is a four to fivefold difference in expression of the master regulator PGC- $1 \alpha$ and other transcription factors between $\mathrm{A} / \mathrm{J}$ and $\mathrm{B} 6$ mice, whereas $U c p 1$ is expressed 80 -fold greater in $\mathrm{A} / \mathrm{J}$ than B6 mice. The regulation of Ucp1 is determined by distinct sites for CREB, ATF2, PPAR $\gamma / \operatorname{PPAR} \alpha, \mathrm{LXR} \alpha, \mathrm{TR}$, and interactions by several of the transcription factors with the co-activator PGC-1 $\alpha$ (Cassard-Doulcier et al., 1993; Kozak et al., 1994; Sears et al., 1996; Puigserver et al., 1998; Hansen and Kristiansen, 2006; Kajimura et al., 2010). PGC-1 $\alpha$ has been shown to be involved in the transcription of $U c p 1$ and additional aspects of mitochondrial biogenesis as co-activator with $\operatorname{PPAR} \gamma / \operatorname{RXR} \alpha$ and $\operatorname{TR} \beta$ in cell culture models (Puigserver et al., 1998). Similarly, mice with a targeted mutation for PPAR $\alpha$ have no suppression of $U c p 1$ expression in liver or retroperitoneal fat (Kersten et al., 1999; Xue et al., 2005). Therefore, transcription factors with well-documented functions in Ucp 1 transcription in vitro often turn out to be non-essential for its expression when inactivated by gene targeting in vivo (Kozak and Koza, 2010). This suggests that many of the sites for transcription of Ucp 1 are in fact redundant and this redundancy involves not only the DNA regulatory motif; but, extends to the factors themselves. The redundancy facilitates the synergy by which many factors can participate in the determination of the expression of $U c p 1$. It becomes evident how the components of the environment, including diet and ambient temperature, exert their effects on $U c p 1$ through their actions on the factors modulating $U c p 1$ expression.

How does this molecular information on the structure and transcription of the $U c p 1$ gene relate to the read out of the brown fat genetic system as we have studied in A/J and B6 and the associated RI lines derived from these mice? A continuous variability occurs in which mRNA levels are positively correlated with $\operatorname{PPAR} \alpha, \mathrm{PGC}-1 \alpha$, and Dio2. We propose that this variability is determined by synergistically interacting genes within the QTLs 
on Chromosomes 2, 3, 8, and 19. Thus, the synergy acts at different levels, at one level on the expression of the transcription and signaling mechanism and at another level on the terminal product of the process, that is, on $U c p 1$ expression.

\section{THE DEVELOPMENT OF A BROWN ADIPOCYTE LINEAGE WITHIN WHITE FAT DEPOTS}

Our QTL studies to identify genes controlling brown adipocytes in white fat depots revealed additional findings of significant interest. Some of these, such as the variable induction among white fat depots, were important from the perspective of selecting the best tissue to conduct the genetic experiment. For example, the differences between A/J and B6 mice was large for the interperitoneal fat depots, although the rank order of expression was retroperitoneal fat $=$ mesenteric fat $\gg$ epididymal fat, while the difference between A/J and B6 mice was small in inguinal fat the level of expression was higher than even retroperitoneal fat (Guerra et al.,
1998). However, a striking finding was that iBAT, while having the highest level of expression, showed no difference between A/J and B6 (Coulter et al., 2003; Xue et al., 2005). We reasoned that if the induction of brown adipocytes recapitulated early development and was based upon the same molecular mechanisms for all brown adipocytes, then if we analyzed gene and protein expression in brown fat during early development in utero and during suckling, $U c p 1$ in interscapular brown fat would be higher in the fetus of $\mathrm{A} / \mathrm{J}$ compared to B6 mice. However, the analysis showed that at no time during development from the fetus in utero until 4 months of age were any strain-dependent differences detected in interscapular brown fat gene expression (Xue et al., 2007; Figure 8). In contrast, expression and histological analysis of retroperitoneal fat showed a transient induction of brown adipocytes between 10 and 30 days of age. Importantly, although brown adipocytes initially appeared in the retroperitoneal fat (we have since found that brown adipocytes are induced in the inguinal fat with essentially

\section{iBAT}

\section{A UcP 1 mRNA}

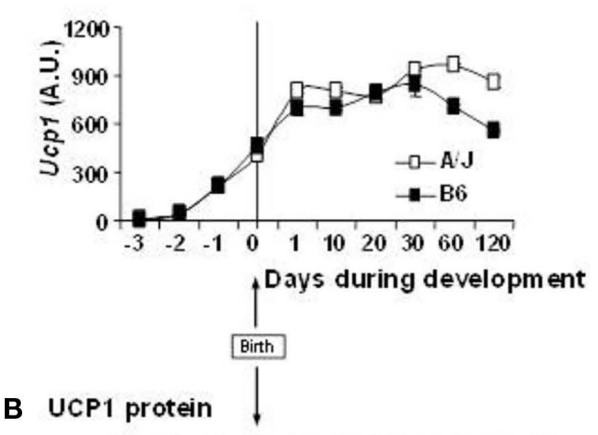

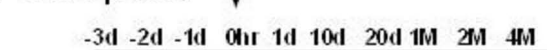

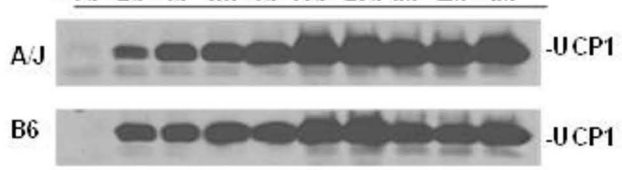

C

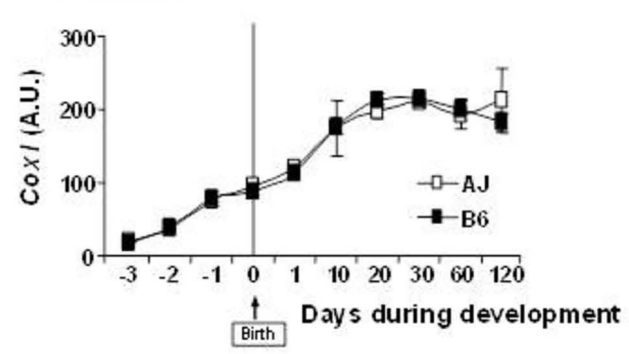

FIGURE 8 | (A) Development of iBAT in A/J and B6. (A) Ucp1 mRNA, (B) UCP1 protein, and (C) mitochondrial DNA content in iBAT of A/J and B6 mice during perinatal and postnatal development. For Ucp1 mRNA, each time point gives the average value from 4 to 9 individual animals analyzed in duplicate and is expressed relative to cyclophilin. Cox 1 mitochondrial DNA levels are expressed relative to the nuclear gene Ucp2 from the analysis of four mice in duplicate. (B). Induction of UCP1
wBAT

A Ucp1 mRNA

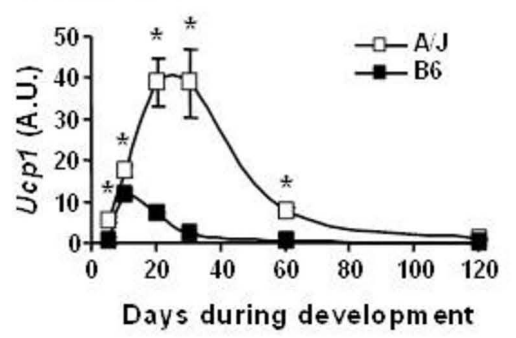

B UCP1 protein

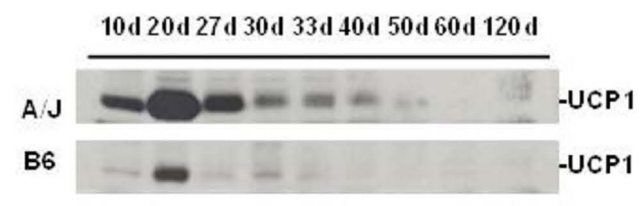

C COXI DNA

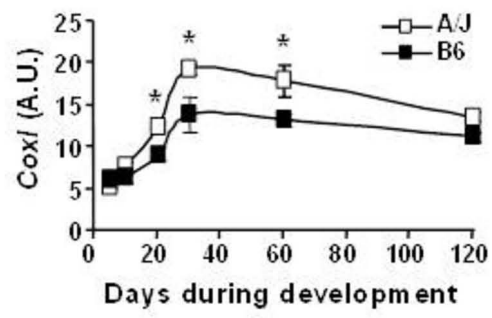

in RP white fat depot in $\mathrm{A} / \mathrm{J}$ and $\mathrm{B} 6$ during postnatal development. (A) Ucp1 mRNA, (B) UCP1 protein, and (C) mitochondrial DNA content in $\mathrm{RP}$ of $\mathrm{A} / \mathrm{J}$ and $\mathrm{B} 6$ during postnatal development. ${ }^{*} P<0.05$ vs. B6. Ucp1 mRNA and Cox 1 DNA is based upon the analysis of three to six animals and Cox1 DNA of four mice per time point. Ucp1 mRNA is expressed relative to cyclophilin, while mitochondrial Cox1 DNA is reported relative to Ucp2. 


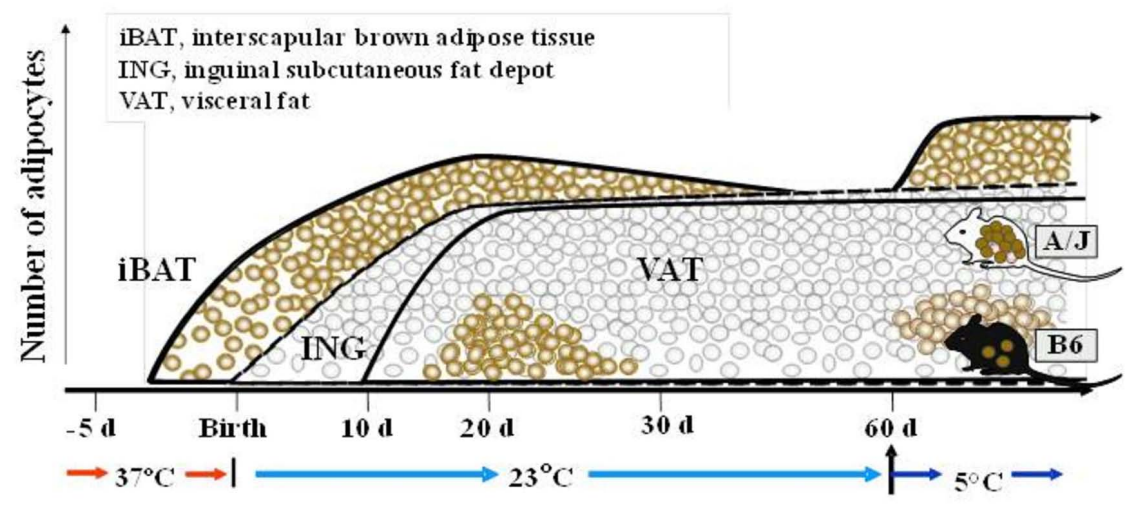

FIGURE 9 | Developmental profiles illustrating the appearance of brown adipocytes in interscapular brown adipose tissue (iBAT) initially at about 4 days before birth. Although the inguinal fat depot (ING) first appears at birth, but the visceral fat (VAT) not until $\sim 10$ days of age, brown adipocytes appear in both depots between 15 and 30 days of age. The induction of brown adipocyte at 20 days of age is higher in $\mathrm{A} / \mathrm{J}$ than $\mathrm{C} 57 \mathrm{BI} / 6 \mathrm{~J}$ (B6) mice, and is induced by in adult animals by adrenergic stimulation in $\mathrm{A} / \mathrm{J}$ mice, but not $\mathrm{B} 6$ mice. This genetic difference in the induction of brown adipocytes among white fat depots is not found in iBAT. This figure has been modified from that found in Xue et al. (2007). the same time course as retroperitoneal fat) of both $\mathrm{A} / \mathrm{J}$ and B6 mice, the process was aborted in the B6 mice before the peak of brown adipocyte expression occurred at approximately 24 days of age (Xue et al., 2007). By 2 months of age the brown adipocytes have essentially disappeared from the white fat; however, if mice are exposed to an ambient temperature of $4^{\circ} \mathrm{C}$ the brown adipocytes are re-induced in $\mathrm{A} / \mathrm{J}$ mice, but not $\mathrm{B} 6$ mice. This genetic variability, characteristic of brown adipocytes found in white fat depots, but not in interscapular brown fat, suggests that the developmental origins of brown adipocytes in interscapular fat are fundamentally different from the brown adipocytes that reside in white fat depots. A conclusion firmly established by the work with PRDM16 and the common progenitor origins for skeletal muscle and iBAT (Seale et al., 2007, 2008).A model of the development of BAT in iBAT and in white fat depots of inducible and non-inducible strain is illustrated in Figure 9.

The absence of genetic variability for a trait in a normal animal suggests that the trait is essential for survival of the animal through its function, in this case the presence of iBAT is essential for maintaining a body temperature at birth (Enerback et al., 1997). The newborn mouse, because of its small size and absence of hair, is particularly susceptible to a cold environment. Consequently, brown fat in the discrete depots in the interscapular region and around vital organs is fully functional at birth. On the other hand, brown adipocytes in white fat depots, which appear at $\sim 20$ days of age, are probably not essential for the maintenance of body temperature and therefore more tolerant of genetic variability. Yet whether UCP1 is essential for survival is confounded by the neonatal pig. The pig has poor thermoregulation and no Ucp 1 in its brown fat due to a deletion of exons 3-5 which occurred about 20 million years ago (Trayhurn et al., 1989; Berg et al., 2006), However, it manages to survive the cold stress of early development, indicating that in the absence of UCP1pigs adapt with alternative mechanisms of thermogenesis. It is interesting that UCP1-deficient mice can also survive the cold if they have a hybrid genetic background, suggesting the importance of novel allelic combinations that can lead to alternative mechanisms of thermogenesis (Hofmann et al., 2001; Anunciado-Koza et al., 2011).

\section{SUMMARY AND PERSPECTIVES}

The intent of this review is to provide a perspective on how to apply the discoveries and lessons of the study of the biology of brown fat in rodents to the upcoming investigations on brown fat in humans. The studies in mice indicate that induction of brown adipocytes in white fat depots is highly effective in reducing obesity when adrenergically stimulated. Because iBAT is relatively constant, we do not know how effective it may be in burning off excess calories when adrenergically stimulated. On the other hand the brown adipocytes which are induced in white fat depots by adrenergic stimulation show a rich potential for variable expression; a variation that has been effective in assessing the ability of brown adipocytes to burn off excess calories. Although we do not have the same depth of knowledge of the transcription and signaling pathways, which has been obtained for iBAT, nevertheless, we know that they can be effectively induced from mature white adipocytes by adrenergic signaling. In other words, simply conditioning the wBAT system by implementing a training program consisting of exposure to a reduced ambient temperature, analogous to physical exercise training, could be another useful weapon in the war against obesity.

\section{ACKNOWLEDGMENTS}

I thank the many post-doctoral and research associates who have worked with me on this fascinating biology during the past 30 years. This work was supported by the Foundation for Polish Science, programme WELCOME, no. WELCOME/2010-4/3 entitled \&\#8221; Nutrition and ambient temperature during early development can reduce susceptibility to obesity \&\#8221; financed by EU Structural Funds in Poland within the Innovative Economy Programme and REFRESH project (FP7-REGPOT-2010-1264103). 


\section{REFERENCES}

Almind, K., Manieri, M., Sivitz, W. I., Cinti, S., and Kahn, C. R. (2007). Ectopic brown adipose tissue in muscle provides a mechanism for differences in risk of metabolic syndrome in mice. Proc. Natl. Acad. Sci. U.S.A. 104, 2366-2371.

Anunciado-Koza, R., Zhang, J., Ukropec, J., Bajpeyi, S., Koza, R. A., Rogers, R. C., Cefalu, W. T., Mynatt, R. L., and Kozak, L. P. (2011). Inactivation of the mitochondrial carrier SLC25A25 (ATP-Mg2+/Pi transporter) reduces physical endurance and metabolic efficiency in mice. $J$. Biol. Chem. 286, 11659-11671.

Bailey, D. W. (1971). Recombinant inbred strains. Transplantation 11, 325-327.

Bartness, T. J., and Bamshad, M. (1998). Innervation of mammalian white adipose tissue: implications for the regulation of total body fat. Am. J. Physiol. 275, R1399-R1411.

Berg, F., Gustafson, U., and Andersson, L. (2006). The uncoupling protein 1 gene (UCP1) is disrupted in the pig lineage: a genetic explanation for poor thermoregulation in piglets. PLoS Genet. 2, e129. doi:10.1371/journal.pgen.0020129

Brem, R. B., and Kruglyak, L. (2005). The lanscape of genetic complexity across 5,700 gene expression traits in yeast. Proc. Natl. Acad. Sci. U.S.A. 102, 1572-1577.

Bukowiecki, L., Collet, A. J., Follea, N., Guay, G., and Jahjah, L. (1982). Brown adipose tissue hyperplasia: a fundamental mechanism of adaptation to cold and hyperphagia. Am. J. Physiol. 242, E353-E359.

Cannon, B., and Nedergaard, J. (2004). Brown adipose tissue: function and physiological significance. Physiol. Rev. 84, 277-359.

Cassard-Doulcier, A. M., Gelly, C., Fox, N., Schrementi, J., Raimbault, S., Klaus, S., Forest, C., Bouillaud, F., and Ricquier, D. (1993). Tissuespecific and beta-adrenergic regulation of the mitochondrial uncoupling protein gene: control by cisacting elements in the $5^{\prime}$ - flanking region. Mol. Endocrinol. 7, 497-506.

Cederberg, A., Gronning, L. M., Ahren, B., Tasken, K., Carlsson, P., and Enerback, S. (2001). FOXC2 is a winged helix gene that counteracts obesity, hypertriglyceridemia, and dietinduced insulin resistance. Cell 106, 563-573.

Champigny, O., Ricquier, D., Blondel, O., Mayers, R. M., Briscoe, M. G., and Holloway, B. R. (1991). Beta 3-adrenergic receptor stimulation restores message and expression of brown-fat mitochondrial uncoupling protein in adult dogs. Proc. Natl. Acad. Sci. U.S.A. 88, 10774-10777.

Christian, M., Kiskinis, E., Debevec, D., Leonardsson, G., White, R., and Parker, M. G. (2005). RIP140targeted repression of gene expression in adipocytes. Mol. Cell. Biol.25, 9383-9391.

Cinti, S. (2002). Adipocyte differentiation and transdifferentiation: plasticity of the adipose organ. J. Endocrinol. Invest. 25, 823-835.

Collins, S., Daniel, K. W., Petro, A. E., and Surwit, R. S. (1997). Strain-specific response to beta 3adrenergic receptor agonist treatment of diet-induced obesity in mice. Endocrinology 138, 405-413.

Coulter, A. A., Bearden, C. M., Liu, X., Koza, R. A., and Kozak, L. P. (2003). Dietary fat interacts with QTLs controlling induction of Pgc1 alpha and Ucpl during conversion of white to brown fat. Physiol. Genomics 14, 139-147.

Cypess, A. M., Lehman, S., Williams, G., Tal, I., Rodman, D., Goldfine, A. B., Kuo, F. C., Palmer, E. L., Tseng, Y. H., Doria, A., Kolodny, G. M., and Kahn, C. R. (2009). Identification and importance of brown adipose tissue in adult humans. N. Engl. J. Med. 360, 1509-1517.

Enerback, S., Jacobsson, A., Simpson, E. M., Guerra, C., Yamashita, H., Harper, M. E., and Kozak, L. P. (1997). Mice lacking mitochondrial uncoupling protein are coldsensitive but not obese. Nature 387, 90-94.

Eppig, J. J., Wigglesworth, K., Varnum, D. S., and Nadeau, J. H. (1996). Genetic regulation of traits essential for spontaneous ovarian teratocarcinogenesis in strain LT/Sv mice: aberrant meiotic cell cycle, oocyte activation, and parthenogenetic development. Cancer Res. 56, 5047-5054.

Giralt, M., Martin, I., Iglesias, R., Vinas, O., Villarroya, F., and Mampel, T. (1990). Ontogeny and perinatal modulation of gene expression in rat brown adipose tissue. Unaltered iodothyronine 5 -deiodinase activity is necessary for the response to environmental temperature at birth. Eur. J. Biochem. 193, 297-302.

Guerra, C., Koza, R. A., Yamashita, H., Walsh, K., and Kozak, L. P. (1998). Emergence of brown adipocytes in white fat in mice is under genetic control. Effects on body weight and adiposity. J. Clin. Invest. 102, 412-420.

Hansen, J. B., Jorgensen, C., Petersen, R. K., Hallenborg, P., De Matteis,
R., Boye, H. A., Petrovic, N., Enerback, S., Nedergaard, J., Cinti, S., Te Riele, H., and Kristiansen, K. (2004). Retinoblastoma protein functions as a molecular switch determining white versus brown adipocyte differentiation. Proc. Natl. Acad. Sci. U.S.A. 101, 4112-4117.

Hansen, J. B., and Kristiansen, K. (2006). Regulatory circuits controlling white versus brown adipocyte differentiation. Biochem. J. 398, 153-168.

Himms-Hagen, J., Cui, J., Danforth, E. Jr., Taatjes, D. J., Lang, S. S., Waters, B. L., and Claus, T. H. (1994). Effect of CL-316,243, a thermogenic beta 3-agonist, on energy balance and brown and white adipose tissues in rats. Am. J. Physiol. 266, R1371R1382.

Himms-Hagen, J., Melnyk, A., Zingaretti, M. C., Ceresi, E., Barbatelli, G., and Cinti, S. (2000). Multilocular fat cells in WAT of CL-316243treated rats derive directly from white adipocytes. Am. J. Physiol. Cell Physiol. 279, C670-C681.

Hirning, U., Schmid, P., Schulz, W. A., Kozak, L. P., and Hameister, H. (1989). In developing brown adipose tissue c-myc protooncogene expression is restricted to early differentiation stages. Cell Differ. Dev. 27, 243-248.

Hofmann, W. E., Liu, X., Bearden, C. M., Harper, M.-E., and Kozak, L. P. (2001). Effects of genetic background on thermoregulation and fatty acid-induced uncoupling of mitochondria in UCP1deficient mice. J. Biol. Chem. 276, 12460-12465.

Houstek, J., Kopecky, J., Rychter, Z., and Soukup, T. (1988). Uncoupling protein in embryonic brown adipose tissue-existence of non thermogenic and thermogenic mitochondria. Biochim. Biophys. Acta 935, 19-25.

Kajimura, S., Seale, P., and Spiegelman, B. M. (2010). Transcriptional control of brown fat development. Cell Metab. 11, 257-262.

Kajimura, S., Seale, P., Tomaru, T., Erdjument-Bromage, H., Cooper, M. P., Ruas, J. L., Chin, S., Tempst, P., Lazar, M. A., and Spiegelman, B. M. (2008). Regulation of the brown and white fat gene programs through a PRDM16/CtBP transcriptional complex. Genes Dev. 22, 1397-1409.

Kersten, S., Seydoux, J., Peters, J. M., Gonzalez, F. J., Desvergne, B., and Wahli, W. (1999). Peroxisome proliferator-activated receptor alpha mediates the adaptive response to fasting. J. Clin. Invest. 103, 1489-1498.
Koza, R. A., Hohmann, S. M., Guerra, C., Rossmeisl, M., and Kozak, L. P. (2000). Synergistic gene interactions control the induction of the mitochondrial uncoupling protein (Ucp1) gene in white fat tissue. $J$. Biol. Chem. 275, 34486-34492.

Kozak, L. P. (2010). Brown fat and the myth of diet-induced thermogenesis. Cell Metab. 11, 263-267.

Kozak, L. P., and Koza, R. A. (2010). The genetics of brown adipose tissue. Prog. Mol. Biol. Transl. Sci. 94, 75-123.

Kozak, U. C., Kopecky, J., Teisinger, J., Enerback, S., Boyer, B., and Kozak, L. P. (1994). An upstream enhancer regulating brown-fat-specific expression of the mitochondrial uncoupling protein gene. Mol. Cell. Biol. 14, 59-67.

Leonardsson, G., Steel, J. H., Christian, M., Pocock, V., Milligan, S., Bell, J., So, P. W., Medina-Gomez, G., VidalPuig, A., White, R., and Parker, M. G. (2004). Nuclear receptor corepressor RIP140 regulates fat accumulation. Proc. Natl. Acad. Sci. U.S.A. 101, 8437-8442.

Nogami, S., Ohya, Y., and Yvert, G. (2007). Genetic complexity and quantitative trait loci mapping of yeast morphological traits. PLoS Genet. 3, e31. doi:10.1371/journal.pgen.0030031

Puigserver, P., Wu, Z., Park, C. W., Graves, R., Wright, M., and Spiegelman, B. M. (1998). A cold-inducible coactivator of nuclear receptors linked to adaptive thermogenesis. Cell 92, 829-839.

Rothwell, N. J., and Stock, M. J. (1979). A role for brown adipose tissue in diet-induced thermogenesis. Nature 281, 31-35.

Seale, P., Bjork, B., Yang, W., Kajimura, S., Chin, S., Kuang, S., Scime, A., Devarakonda, S., Conroe, H. M., Erdjument-Bromage, H., Tempst, P., Rudnicki, M. A., Beier, D. R., and Spiegelman, B. M. (2008). PRDM16 controls a brown fat/skeletal muscle switch. Nature 454, 961-967.

Seale, P., Kajimura, S., Yang, W., Chin, S., Rohas, L. M., Uldry, M., Tavernier, G., Langin, D., and Spiegelman, B. M. (2007). Transcriptional control of brown fat determination by PRDM16. Cell Metab. 6, 38-54.

Sears, I. B., Macginnitie, M. A., Kovacs, L. G., and Graves, R. A. (1996). Differentiation-dependent expression of the brown adipocyte uncoupling protein gene: regulation by peroxisome proliferatoractivated receptor gamma. Mol. Cell. Biol. 16, 3410-3419. 
Seldin, M. F., Mott, D., Bhat, D., Petro, A., Kuhn, C. M., Kingsmore, S. F., Bogardus, C., Opara, E., Feinglos, M. N., and Surwit, R. S. (1994). Glycogen synthase: a putative locus for diet-induced hyperglycemia. J. Clin. Invest. 94, 269-276.

Shockley, K. R., and Churchill, G. A. (2006). Gene expression analysis of mouse chromosome substitution strains. Mamm. Genome 17, 598-614.

Smith, R. E., and Horwitz, B. A. (1969). Brown fat and thermogenesis. Physiol. Rev. 49, 330-425.

Staszkiewicz, J., Gimble, J., Cain, C., Dietrich, M., Burk, D., KirkBallard, H., and Gawronska-Kozak, B. (2009). Flow cytometric and immunohistochemical detection of in vivo BrdU-labeled cells in mouse fat depots. Biochem.
Biophys. Res. Commun. 378, 539-544.

Taylor, B. A. (1981). "Recombinant inbred strains," in Genetic Variants and Strains of the Laboratory Mouse, ed. M. C. Green (New York: Gustav Fischer Verlag). 397-407.

Trayhurn, P., Temple, N. J., and Van Aerde, J. (1989). Evidence from immunoblotting studies on uncoupling protein that brown adipose tissue is not present in the domestic pig. Can. J. Physiol. Pharmacol. 67, 1480-1485.

Van Marken Lichtenbelt, W. D., Vanhommerig, J. W., Smulders, N. M., Drossaerts, J. M., Kemerink, G. J., Bouvy, N. D., Schrauwen, P., and Teule, G. J. (2009). Cold-activated brown adipose tissue in healthy men. N. Engl. J. Med. 360, 1500-1508.

Virtanen, K. A., Lidell, M. E., Orava, J., Heglind, M., Westergren, R., Niemi,
T., Taittonen, M., Laine, J., Savisto, N. J., Enerback, S., and Nuutila, P. (2009). Functional brown adipose tissue in healthy adults. N. Engl. J. Med. 360, 1518-1525.

Xue, B., Coulter, A., Rim, J. S., Koza, R. A., and Kozak, L. P. (2005). Transcriptional synergy and the regulation of Ucpl during brown adipocyte induction in white fat depots. Mol. Cell. Biol. 25, 8311-8322.

Xue, B., Rim, J. S., Hogan, J. C., Coulter, A. A., Koza, R. A., and Kozak, L. P. (2007). Genetic variability affects the development of brown adipocytes in white fat but not in interscapular brown fat. J. Lipid Res. 48, 41-51.

Conflict of Interest Statement: The author declares that the research was conducted in the absence of any commercial or financial relationships that could be construed as a potential conflict of interest.

Received: 18 August 2011; paper pending published: 15 September 2011; accepted: 12 October 2011; published online: 31 October 2011.

Citation: Kozak LP (2011) The genetics of brown adipocyte induction in white fat depots. Front. Endocrin. 2:64. doi: 10.3389/fendo.2011.00064

This article was submitted to Frontiers in Cellular Endocrinology, a specialty of Frontiers in Endocrinology.

Copyright $($ C 2011 Kozak. This is an openaccess article subject to a non-exclusive license between the authors and Frontiers Media SA, which permits use, distribution and reproduction in other forums, provided the original authors and source are credited and other Frontiers conditions are complied with. 